\title{
Testing of an Amine-Based Pressure-Swing System for Carbon Dioxide and Humidity Control
}

\author{
Amy Lin \\ Jacobs Technology \\ Frederick Smith, Jeffrey Sweterlitsch, and John Graf \\ NASA Johnson Space Center \\ Tim Nalette, William Papale, and Melissa Campbell \\ Hamilton Sundstrand \\ Sao-Dung Lu \\ MEI Technologies
}

Copyright @ 2007 SAE International

\begin{abstract}
In a crewed spacecraft environment, atmospheric carbon dioxide $\left(\mathrm{CO}_{2}\right)$ and moisture control is crucial. Hamilton Sundstrand has developed a stable and efficient aminebased $\mathrm{CO}_{2}$ and water vapor sorbent, SA9T, that is wellsuited for use in a spacecraft environment. The sorbent is efficiently packaged in pressure-swing regenerable beds that are thermally linked to improve removal efficiency and minimize vehicle thermal loads. Flows are all controlled with a single spool valve. This technology has been baselined for the new Orion spacecraft. However, more data was needed on the operational characteristics of the package in a simulated spacecraft environment. A unit was therefore tested with simulated metabolic loads in a closed chamber at Johnson Space Center during the last third of 2006. Tests were run at a variety of cabin temperatures and with a range of operating conditions varying cycle time, vacuum pressure, air flow rate, and crew activity levels. Results of this testing are presented and potential flight operational strategies discussed.
\end{abstract}

\section{INTRODUCTION}

Human beings produce carbon dioxide $\left(\mathrm{CO}_{2}\right)$ when they breathe, but too high a concentration in the atmosphere around them can quickly become toxic. For this reason, $\mathrm{CO}_{2}$ control is critical in the closed environment of a spacecraft. Humans also breathe out water vapor and exchange water vapor with the atmosphere through their skins. While excessive water vapor is not dangerous to humans, it can be uncomfortable, and it can be hazardous to the electronic equipment in a spacecraft cabin.
In the past, spacecraft have typically used separate systems to control $\mathrm{CO}_{2}$ and humidity. Common $\mathrm{CO}_{2}$ control methods have included sorption by lithium hydroxide or zeolite compounds, while water has typically been collected by condensing heat exchangers. However, the chemical sorption systems have tended to be large and heavy, whether regenerable or not, and condensate water collection systems require significant support by a lower-temperature thermal control system.

As an alternative to traditional $\mathrm{CO}_{2}$ sorption systems, Hamilton Sundstrand has spent many years developing amine-based vacuum-regenerated adsorption systems. The first major implementation of this type of system, known as the Regenerative $\mathrm{CO}_{2}$ Removal System (RCRS), was tested on the Space Shuttle in the early 1990s. This design and the associated amine have gone through a number of improvement cycles in the intervening years. The current iteration of the system uses a pair of interleaved-layer beds filled with pellets coated in a sorbent known as SA9T to remove carbon dioxide $\left(\mathrm{CO}_{2}\right)$ and water $\left(\mathrm{H}_{2} \mathrm{O}\right)$ vapor from a spacecraft cabin atmosphere.

SA9T, in addition to being a good $\mathrm{CO}_{2}$ sorbent, also has a great affinity for water vapor. When removing water vapor from the cabin atmosphere with a regenerable sorbent instead of a traditional condensing heat exchanger, the spacecraft cooling system can be greatly simplified by eliminating the need for a low-temperature cooling loop and a fairly significant heat load. Hamilton Sundstrand studies have shown the amine to be very stable over long periods and the interleaved bed system minimizes total cabin heat loads due to the adsorption and desorption processes. For these and other reasons, this technology was considered a good candidate for the 
primary $\mathrm{CO}_{2}$ and water vapor removal device by both of the prime contract bidders for the new Orion spacecraft contract.

While Hamilton Sundstrand's technology was already relatively well developed and had undergone subscale and open-loop testing, NASA's Exploration Life Support (ELS) and Orion development groups wanted more details on the performance of the device in a realistic spacecraft environment. The ELS Air Revitalization Systems team at Johnson Space Center (JSC) was tasked with refitting an existing test chamber, called the Air Revitalization Technology Integration Chamber (ARTIC), to test Hamilton Sundstrand's technology, which the Air Revitalization team calls the $\mathrm{CO}_{2}$ And Moisture Removal Amine Swing-bed, or CAMRAS.

The JSC team built the test rig for a single CAMRAS unit during the first half of 2006 and performed two series of tests on the unit between August and December of 2006. The primary objectives of the tests were to evaluate the performance of the CAMRAS under various conditions in order to recommend implementation details if the technology were selected to be incorporated into the Orion spacecraft. Phase 1 testing established baseline performance data. Phase 2 better refined the performance of the CAMRAS under different operational conditions and investigated an extended metabolic profile scenario. Testing is scheduled to continue in 2007. Preliminary results of only the first two phases of testing are presented here, along with key lessons learned and preliminary recommendations for physical and operational implementation of the CAMRAS in the Orion vehicle.

\section{TEST RIG DESCRIPTION}

Figure 1 shows a functional overview of the rig used to test the CAMRAS at JSC. It is briefly described in the following subsections. For additional information on the CAMRAS test rig, see the 2007 ICES paper by SaoDung Lu, number 07ICES-XXX. A photo of the test article inside the chamber is presented in Figure 2.

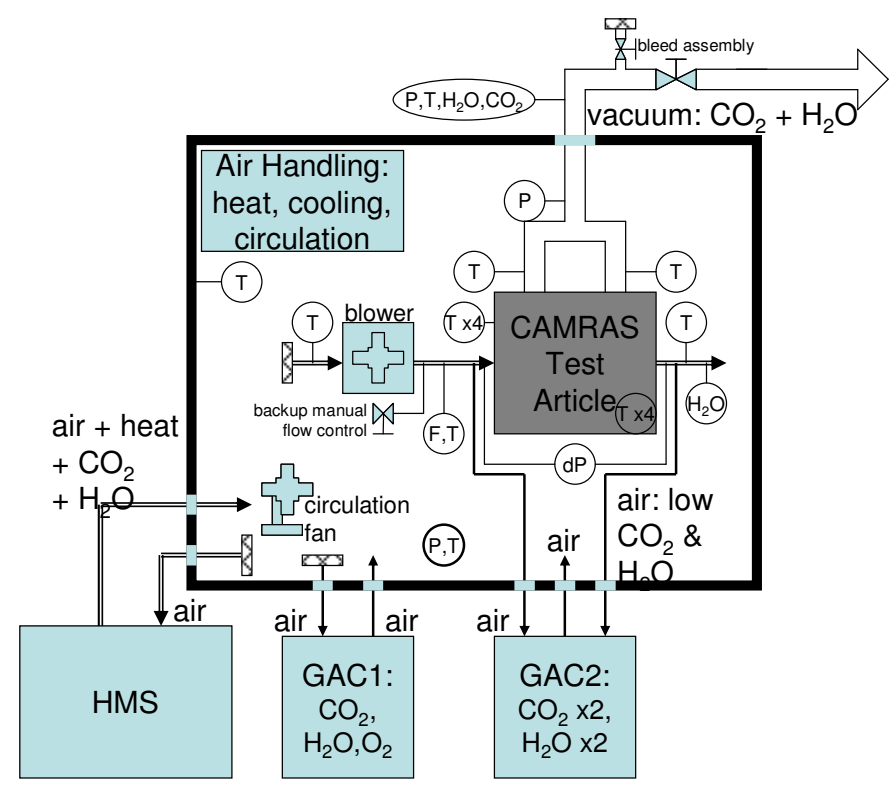

Figure 1 - CAMRAS Test Rig Functional Overview

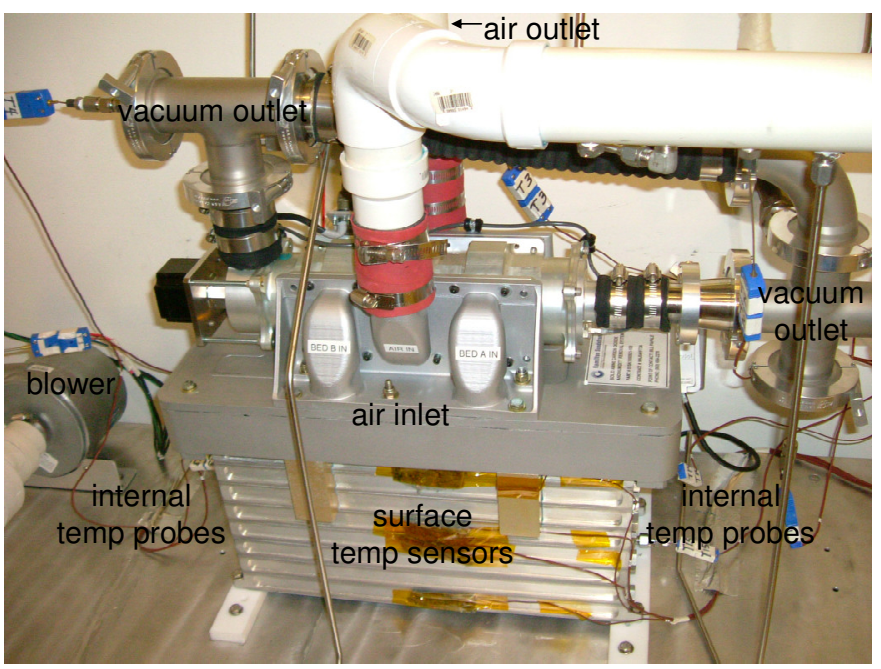

Figure 2 - CAMRAS Test Article Inside Test Chamber

\section{TEST ARTICLE}

As previously mentioned, the CAMRAS technology uses a pair of interleaved-layer beds filled with sorbent pellets. In each CAMRAS, a spool-type valve directs airflow from the cabin through the adsorbing bed and back to the cabin while isolating the desorbing bed to a direct line to space vacuum. The valve periodically switches position, swapping the bed functions and equalizing pressure between the beds as it travels, which helps minimize ullage air losses. Each adsorption or desorption period is called a half-cycle. Figure 3 shows a simple schematic of the CAMRAS operation. 


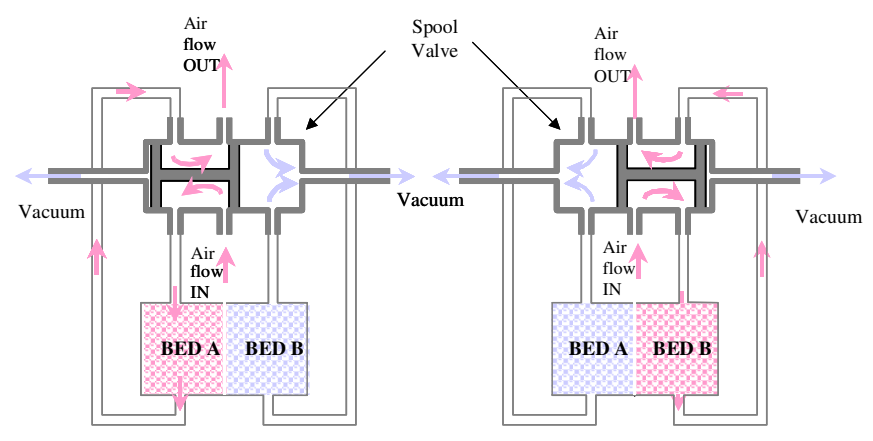

Figure 3 - CAMRAS Process Flow

The highly porous pellets in this device are coated with a liquid amine, which becomes immobilized in the pellet pores. In this sorbent system, known as SA9T, the amine adsorbs both carbon dioxide and water. The $\mathrm{CO}_{2}$ adsorption reaction generates some heat, while the vacuum-desorption reaction consumes heat; the interleaving of bed layers helps conserve the overall system thermal energy and no direct heating or cooling is required.

In the projected Orion application of this technology, three separate CAMRAS assemblies will be installed in the vehicle. Two will operate in parallel for a crew of four to six people, and the third will be reserved as a spare. The beds are sized such that, in an emergency, a single CAMRAS could maintain the cabin $\mathrm{CO}_{2}$ at threshold safe levels for a crew of six indefinitely. In these tests only a single CAMRAS was available, so most of the scenarios were performed in the conditions a single unit would be expected to support (half the cabin volume and half the crew).

\section{TEST CHAMBER}

The ARTIC test chamber is a closed and sealed environment directly monitored for temperature and pressure. The chamber air conditions were also analyzed by an external sampling rack for dew point and for $\mathrm{CO}_{2}$ and $\mathrm{O}_{2}$ concentrations. The volume of the chamber was somewhat larger than the volume of the Crew Exploration Vehicle (CEV, now known as Orion) when the facility requirements were defined. The total free volume was therefore reduced to approximately 430 $\mathrm{ft}^{3}$ by a sealed aluminum sheet wall constructed inside the chamber. The chamber leak rate was determined by a $\mathrm{CO}_{2}$ decay test with the external air loop systems active and running. Total leakage rates were determined to be $1.4 \%$ per day before the beginning of CAMRAS testing. Inside the chamber is a condensing heat exchanger with blower that was run with the coolant loop above condensing temperatures in all of the CAMRAS tests. An electric heater is also present inside the chamber if elevated temperatures are required, and an additional freestanding fan can be used to improve circulation. Because the test article was designed to do half the work nominally needed in the CEV, the chamber volume was further reduced to about $6.20 \mathrm{~m}^{3}$, or half the projected vehicle free volume, with airtight space-filling boxes for most of the test scenarios.
METABOLIC SIMULATION

A Human Metabolic Simulator (HMS) is used with the chamber for this testing. It is designed to simulate human production of heat, $\mathrm{CO}_{2}$, and exhaled $\mathrm{H}_{2} \mathrm{O}$ vapor. The heat production function is considered extraneous to CAMRAS testing, but incidental heat is added to the atmosphere as part of the steam generation process used to represent metabolic water production. Liquid water is pumped into a hot oil/water heat exchanger at a metered rate, the resulting steam is allowed to achieve slight pressurization (up to about $69 \mathrm{kPa}$ gauge), and the steam is then injected directly into the HMS air flow stream. $\mathrm{CO}_{2}$ is separately injected into the HMS air stream from a pressurized and flow-controlled gas source.

The HMS can simulate at least eight people at once, though the Phase 1 and 2 CAMRAS tests were typically run with a load of two or three people. Table 1 lists the metabolic constituent generation rates used in this CAMRAS testing, which are simply doubled when metabolic loads of four or six people are tested. These rates are based on NASA's latest Human Systems Integration Requirements and represent 82-kg males.

\begin{tabular}{|c|c|c|c|c|c|}
\hline $\begin{array}{l}\text { Crew Size } \\
\text { \& Activity }\end{array}$ & $\begin{array}{l}\frac{0}{d} \\
\frac{\mathbb{d}}{\omega} \\
\sim\end{array}$ & 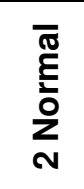 & 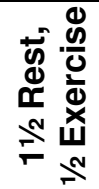 & $\begin{array}{l}\frac{0}{d} \\
\frac{\Phi}{\omega} \\
\infty\end{array}$ & 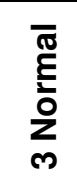 \\
\hline $\begin{array}{l}\text { Metabolic } \mathrm{CO}_{2} \\
\text { Generation } \\
\text { Rate }(\mathrm{g} / \mathrm{min})\end{array}$ & 0.94 & 1.57 & $\begin{array}{l}\text { peak } \\
3.67\end{array}$ & 1.41 & 2.36 \\
\hline $\begin{array}{l}\text { Metabolic } \mathrm{H}_{2} \mathrm{O} \\
\text { Generation } \\
\text { Rate }(\mathrm{g} / \mathrm{min})\end{array}$ & 1.16 & 1.66 & $\begin{array}{l}\text { peak } \\
10.16\end{array}$ & 1.75 & 2.49 \\
\hline
\end{tabular}

Table 1 - Human Systems Integration Requirements Metabolic Constituent Generation Rates Used in CAMRAS Testing

Early in the test the steam injection technique was not well understood and was consequently not well managed. Data from these early tests shows regularly fluctuating chamber dew points as a result of inconstant steam injection, and the best guess at an average often stands in for a stable reading. Later in the testing this was better understood and better managed, but many cases still experienced some variability in dew point levels as a result of the significant artistry required to manually control the requisite valve positions to maintain the right amount of steam backpressure.

\section{TEST ARTICLE AIR SIDE}

The CAMRAS was outfitted with a variable-speed blower with flow meter, a differential pressure sensor between the canister inlet and outlet, and temperature sensors at various locations in the air path, including four on the external surface of the canister and four more probes inside the amine beds. Samples from the inlet and outlet lines were also pulled through an external sampling rack, 
where dew point and $\mathrm{CO}_{2}$ concentration were measured. A thin-film aluminum oxide moisture sensor probe in the outlet line supplemented the readings from the chilled mirror analyzer in the external rack.

Dew point sensing was a difficult issue throughout the Phase 1 and 2 testing. The dew point sensors that were intended to be the primary data sources throughout the tests were of the chilled mirror variety. However, as testing progressed, it became more and more apparent that for some portions of the CAMRAS testing they were not particularly effective, and implementation issues further complicated the problems.

Testing began with EG\&G (Edgetech) DewPrime I chilled mirror analyzers working on continuous sample streams pulled out of the chamber. These were later changed out to GE Optica chilled mirror analyzers with $1211 \mathrm{H}$ heads. The different analyzers did have their pros and cons relative to one another, but on the whole, the chilled mirror style analyzer did not work well with dew points regularly running near or below the freezing point. They were especially ill-suited to reading the CAMRAS outlet dew points, which can swing up to $20^{\circ} \mathrm{C}$ down and back up during a single 6.5-minute half-cycle. The aluminum oxide probe (GE Panametrics) proved much more reliable for measuring the outlet dew points and it was relied upon for that.

Complicating the issues with the chilled mirror analyzers were sample flow issues discovered late in Phase 2 testing. Although cross-checks had been regularly performed on the CAMRAS inlet and outlet readings, there was often an offset between the CAMRAS inlet readings from both chilled mirror analyzers and the separate chamber chilled mirror reading. After much investigation, it was discovered that some poor choices in plumbing design and flow limitation inside the sampling racks were throwing off the readings of both the inlet and outlet analyzers by as much as $3^{\circ} \mathrm{C}$.

The data presented in this paper tries to take these issues into account, but some inconsistencies between older and more recent data may remain.

\section{TEST ARTICLE VACUUM SIDE}

As the CAMRAS is designed to desorb the adsorbed gases to space, a vacuum source was required for this testing. This proved one of the more complicated systems to implement, principally due to the relatively high water load as compared to most vacuum pump operating environments. Water vapor is always difficult to deal with in vacuum systems, as its polar molecules tend to "stick" to the inner surfaces of vacuum lines and therefore are slow to be pulled downstream, which causes the pressure in the vacuum line to be higher than desired.

After a couple of inadequate setups were tried, success was attained by using a system of pumps designed to evacuate an entire (other) chamber for space suit testing. A pair of parallel Roots blowers upstream of a large rotary piston pump and connected to the test article via long but large vacuum lines was able to provide pressures of as little as $0.2 \mathrm{mmHg}$ at the test article when the test article was idle. This is called the base pressure. When the CAMRAS operates, there is a brief pulse of gas dumped into the vacuum system every time the spool valve changes position, and the pressure then falls off exponentially. The relatively steady pressure toward the end of each half-cycle is called the cycling pressure, and was easily maintained below $0.5 \mathrm{mmHg}$ during most of the test cases once the final system was in use.

A mass spectrometer was intended to be hooked up to the vacuum line to monitor relative proportions of water vapor and carbon dioxide in the effluent stream, as well as to monitor for other trace chemicals being desorbed from the CAMRAS, but it was not implemented in time to provide data for either Phase 1 or Phase 2 tests.

\section{TEST CASES}

The testing presented here was conducted in two phases. Phase 1 testing established baseline performance data in a few nominal operations situations and touched on other operational scenarios. Phase 2 was dedicated primarily to better refining the performance of the CAMRAS with a range of air flow rates and pressure-swing cycle times, but also investigated an extended three-day scenario including a realistic profile of normal, sleep, and exercise metabolic loads.

- Both phases featured re-creations of select predelivery Hamilton Sundstrand cases intended to help compare effects of differing test rigs. The Phase 1 tests were run with the original inadequate vacuum system and not rerun due to time constraints. They were instead rerun as part of Phase 2, with the same vacuum system used for all the rest of the Phase 1 and Phase 2 tests.

- Phase 1 included:

- "Baseline" tests with normal metabolic loads for smaller and larger crews.

- Degraded vacuum condition testing (simulating long and/or narrow vehicle vacuum lines).

- Sleep metabolic load tests for smaller and larger crews.

- Exercise metabolic load test for a smaller crew (a larger crew would not have space to exercise).

- Failure-scenario tests, including:

- A large crew all on one CAMRAS.

- A large crew all on one CAMRAS with increased blower speed.

- A large crew on two CAMRAS units but with reduced blower speed.

- De-orbit and landing scenario with smaller and larger crews.

- Launch and ascent scenario with smaller and larger crews. 
- Varied cabin temperature condition testing.

- Phase 2 built on the baseline and failure scenarios of Phase 1 by testing a matrix of blower speed and spool valve cycle time combinations.

- Three tests cases in Phase 2 examined the possible effects of $\mathrm{CO}_{2}$ and $\mathrm{H}_{2} \mathrm{O}$ co-adsorption on the CAMRAS operation.

- Phase 2 also included a 72-hour test in which the simulated smaller crew spent realistic time periods at sleep, normal, and exercise metabolic activity levels.

Toward the beginning of the testing, control of starting conditions was rigorously implemented. As testing and modeling matured, however, it became apparent that the final conditions weren't dependent on initial conditions for most constant metabolic load cases, and only the duration needed to complete the case was affected. Most later runs were not particularly attentive to initial condition details except to the extent needed to try to minimize the duration of the test case.

In general, the criteria for a test case to be considered complete was the chamber and CAMRAS inlet conditions offering dynamically stable readings for an hour. In practice, this was interpreted as a requirement for no significant directionality over the course of an hour to readings that were inherently slightly unstable due to the overall system design and CAMRAS functionality. For several cases, the completion criteria was when the cabin $\mathrm{CO}_{2}$ concentration exceeded $1 \%(7.6 \mathrm{mmHg})$. Some cases simply could not be completed in the available time, but were continued as long as possible so that the final conditions might be extrapolated.

\section{TEST RESULTS}

\section{VENDOR COMPARISON TESTS}

Three Hamilton Sundstrand cases were re-created as part of the Phase 1 and Phase 2 testing. The setup for the JSC tests was somewhat different than the vendor's rig. While the vendor was injecting water and carbon dioxide into the CAMRAS inlet line to create specified inlet conditions and then evaluating the CAMRAS outlet air flow to determine the removal rates, the JSC team instead had to try to balance the CAMRAS effects on the test chamber atmosphere by varying the HMS input rates to maintain the chamber at the desired atmospheric conditions. Note that constituent injection rates were not based on metabolic rates in these tests. Another key difference is that the vendor test rig had the CAMRAS exterior exposed to lab temperatures while the JSC rig was exposed to the generally higher chamber temperatures. Temperature affects adsorption and desorption rates. The Phase 1 tests were run on a vacuum system that could not maintain acceptable cycling vacuum pressures (below $1 \mathrm{mmHg}$ ) and the results were thus not especially stable or conclusive. All tests were conducted with 6.5-minute half-cycle times. Table 2 compares the results of the three cases in all three test series.

\begin{tabular}{|c|c|c|c|c|c|c|}
\hline $\begin{array}{l}\text { Test } \\
\text { Group }\end{array}$ & 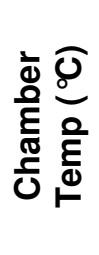 & 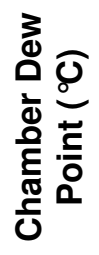 & 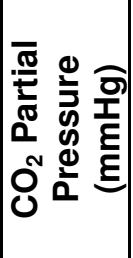 & 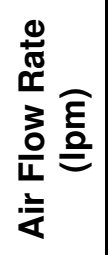 & 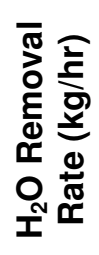 & 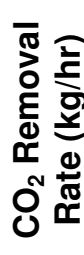 \\
\hline Hamilton & 28.2 & 5.3 & 2.94 & 748 & 0.24 & 0.22 \\
\hline Phase 1 & 26.7 & & & 708 & 0.20 & 0.17 \\
\hline Phase 2 & 26.7 & 1.9 & 2.89 & 708 & 0.21 & 0.19 \\
\hline Hamilton & 26.1 & 5.9 & 7.40 & 742 & 0.25 & 0.42 \\
\hline Phase 1 & 26.7 & & & 708 & 0.23 & 0.36 \\
\hline Phase 2 & 26.7 & 2.8 & 7.37 & 708 & 0.21 & 0.40 \\
\hline Hamilton & 30.2 & 21.8 & 3.15 & 733 & 0.68 & 0.22 \\
\hline Phase 1 & 29.4 & & & 708 & 0.62 & 0.17 \\
\hline Phase 2 & 29.4 & 20.9 & 3.04 & 708 & 0.73 & 0.16 \\
\hline
\end{tabular}

Table 2 - Comparison of Hamilton Sundstrand Open-Loop and JSC Pseudo-Open-Loop Test Results

\section{SINGLE CONSTITUENT CASES}

The vendor comparison test results suggest that the CAMRAS efficiencies for carbon dioxide and water change somewhat depending on the relative quantities of the two constituents in the atmosphere. To further investigate this phenomenon, in Phase 2 a set of three cases was run with the same type of "maintain the chamber conditions" strategy as the vendor comparison cases. In these cases, however, the extremes of this theory were investigated to attempt to determine the extent of possible co-adsorption effects at the amine level. One case was run to first find the constituent injection rates required to maintain both high water vapor and high $\mathrm{CO}_{2}$ chamber levels. One case was then run with the same dew point but effectively zero $\mathrm{CO}_{2}$ concentration, and the last case maintained the high $\mathrm{CO}_{2}$ concentration of the first case in an exceedingly dry atmosphere (dew point below $-20^{\circ} \mathrm{C}$ ). The results of these cases are presented in Table 3.

\begin{tabular}{|c|c|c|c|c|c|c|}
\hline Test Point & 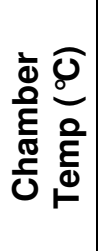 & 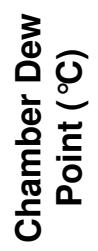 & 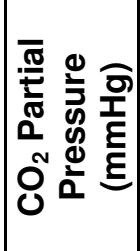 & 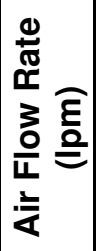 & 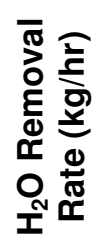 & 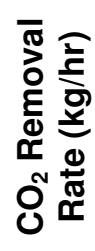 \\
\hline & 9.4 & 21.8 & 7.98 & 708 & 0.73 & 0.35 \\
\hline $\mathrm{H}_{2} \mathrm{C}$ & 29.4 & 21.7 & 0 & 708 & 0.74 & 0 \\
\hline $\mathrm{CO}_{2}$ Only & 29.4 & -30.5 & 7.22 & 708 & 0 & 0.37 \\
\hline
\end{tabular}

Table 3 - Singe-Constituent Pseudo-Open-Loop Test Results

It seems that the CAMRAS has more capacity for $\mathrm{CO}_{2}$ when there is no water present to compete for active reaction sites on the amine-coated beads, and the reverse also seems to be true, though to a far lesser extent. However, differing reaction temperatures probably factor into this. $\mathrm{CO}_{2}$ alone caused the bed 
temperatures to vary only $\pm 3-4^{\circ} \mathrm{C}$ from the inlet temperature, while the combined load and the water-only load caused bed temperatures to vary some $\pm 8^{\circ} \mathrm{C}$ from the inlet temperature. According to Hamilton Sundstrand engineers, $\mathrm{CO}_{2}$ is adsorbed better at lower temperatures. Heat transfer within the CAMRAS unit and testing with metabolic loads at a variety of temperatures are further discussed later in this paper.

\section{BASELINE AND MATRIX CASES}

Early in Phase 1 "Baseline" cases were run which established a norm for comparison with later cases. These were run for both a smaller crew and a larger crew using the standard $708 \mathrm{lpm}$ air flow rate and 6.5minute spool valve cycle time in a $21^{\circ} \mathrm{C}$ chamber. At the time they were run, however, the HMS steam injection management technique was not refined, and steam was periodically pulsed into the lines instead of flowing slowly and steadily. The cabin dew points were not entirely stable as a result, so the best estimate of what the stable reading would be was used. There is also some question of the validity of the dew point readings due to various factors. During the long test in Phase 2, the smaller crew baseline conditions were recreated with more data confidence, and both baselines will be checked again in future testing.

For the smaller crew (simulating a total crew complement of four in a volume of ), Phase 1 results were interpreted to yield a dew point around $-4^{\circ} \mathrm{C}$ and a $\mathrm{CO}_{2}$ partial pressure of $1.5 \mathrm{mmHg}$. During the long test in Phase 2, however, those results were repeatably around $-9^{\circ} \mathrm{C}$ and $1.7 \mathrm{mmHg}$. For the larger crew (simulating a total crew complement of six), Phase 1 results were interpreted to yield a dew point around $0^{\circ} \mathrm{C}$ and a $\mathrm{CO}_{2}$ partial pressure of $2.2 \mathrm{mmHg}$.

The baseline cases for the larger crew also fed directly into a matrix of test cases run in Phase 2 which examined the effects of varying both cycle time and air flow rate. All the Phase 2 matrix cases were performed with a metabolic load equivalent to six crew at a normal activity level. The preliminary results of the matrix cases are presented in Table 4. An ' $\mathrm{X}$ ' for the $\mathrm{CO}_{2}$ reading indicates that the steady state $\mathrm{CO}_{2}$ concentration exceeded the $1.00 \%(7.6 \mathrm{mmHg})$ safety limit and thus the operating parameter combination is unsuitable for that metabolic load. Note that the seemingly-unusual air flow rates in the table are equivalent to $5,15,25$, and 35 $\mathrm{cfm}$. About half of these tests were performed before the dew point analyzer troubleshooting, and about half afterward.

\begin{tabular}{|c|c|c|c|c|}
\hline Air Flow (Ipm) & \multirow{2}{*}{142} & \multirow{2}{*}{425} & \multirow{2}{*}{708} & \multirow{2}{*}{991} \\
\hline Cycle Time (min) & & & & \\
\hline 5 & $\begin{array}{c}18^{\circ} \mathrm{C}^{*} \\
X\end{array}$ & $\begin{array}{c}3^{\circ} \mathrm{C} \\
0.40 \%\end{array}$ & & $\begin{array}{c}-7^{\circ} \mathrm{C} \\
0.21 \%\end{array}$ \\
\hline 6.5 & $\begin{array}{c}19^{\circ} \mathrm{C}^{*} \\
\mathrm{X}\end{array}$ & & $\begin{array}{c}-1{ }^{\circ} \mathrm{C} \\
0.28 \%\end{array}$ & \\
\hline 10 & & & & $\begin{array}{c}-4^{\circ} \mathrm{C} \\
0.28 \%\end{array}$ \\
\hline 15 & & $\begin{array}{c}3^{\circ} \mathrm{C} \\
0.47 \%\end{array}$ & $\begin{array}{c}-1^{\circ} \mathrm{C} \\
0.40 \%\end{array}$ & \\
\hline 22.5 & & $\begin{array}{c}3^{\circ} \mathrm{C} \\
0.67 \%\end{array}$ & $\begin{array}{c}2^{\circ} \mathrm{C} \\
0.60 \%\end{array}$ & \\
\hline 30 & & $\begin{array}{c}4{ }^{\circ} \mathrm{C} \\
\mathrm{X}\end{array}$ & $\begin{array}{c}3^{\circ} \mathrm{C} \\
\mathrm{X}\end{array}$ & $\begin{array}{c}4^{\circ} \mathrm{C}^{*} \\
\mathrm{X}\end{array}$ \\
\hline
\end{tabular}

${ }^{*}$ Case had not reached steady state by the end of the test day

Table 4 - Preliminary Larger Crew Matrix Tests Results: Chamber Dew Points and $\mathrm{CO} 2$ Concentrations

It will be important to identify operational settings that will yield a high enough dew point for the crew's comfort (generally between 4 and $15^{\circ} \mathrm{C}$ ) and $\mathrm{CO}_{2}$ concentrations low enough to stay well within safe limits for long term exposure. $\mathrm{CO}_{2}$ drops rapidly as flow rate is increased, and moderately as cycle-time is shortened. Similarly, dew points drop a little as flow rate is increased, and slightly less as cycle time is increased. The ideal operating point for normal operations, therefore, most likely lies above a diagonal line from the lower left corner to the upper right corner of Table 4. Additional matrix cases will be performed in future tests to further refine appropriate operational setting combinations.

\section{SLEEP METABOLIC LOADS}

As an extension of the baseline cases, which were run with normal waking metabolic loads, CAMRAS effects on the cabin atmosphere with the crew producing sleep metabolic loads were also investigated. Again, this scenario was run for both a smaller and larger crew with the CAMRAS operating at the standard $708 \mathrm{lpm}$ of air flow and 6.5-minute cycle times. For the smaller crew, conditions that seemed nearly stable at the end of the test day yielded a cabin $\mathrm{CO}_{2}$ concentration of $0.14 \%$ and a dew point of $-11.9^{\circ} \mathrm{C}$. During the long test in Phase 2, however, it became apparent that the cabin dew point might keep dropping to $-13^{\circ} \mathrm{C}$ or lower over the course of a sleep period. For the larger crew, stable chamber conditions were $0.18 \% \mathrm{CO}_{2}$ concentration and $-6.9^{\circ} \mathrm{C}$.

\section{EXERCISE METABOLIC LOADS}

Exercise metabolic loads, unlike normal and sleep loads, are not steady. For CAMRAS testing, each of four crew members was assumed to exercise in succession for 30 minutes each, with a 15-minute break between. Water vapor loads are higher after the first exerciser's active period because the first exerciser is still sweating and cooling down for an hour. Including cool down periods, an exercise scenario of this type lasts nearly four hours. Due to the nature of the HMS design, the smooth curves of an exercise water vapor load could not be precisely 
replicated, and were instead approximated by step changes in input rate setpoints every eight (Phase 1) or seven and a half (Phase 2) minutes. The water load target and approximations are shown in Figure 4. $\mathrm{CO}_{2}$ loads, in contrast, are naturally nearly step functions, increasing only when a crewperson is exercising, and returning to normal when he stops, and they were simulated as such by the HMS.

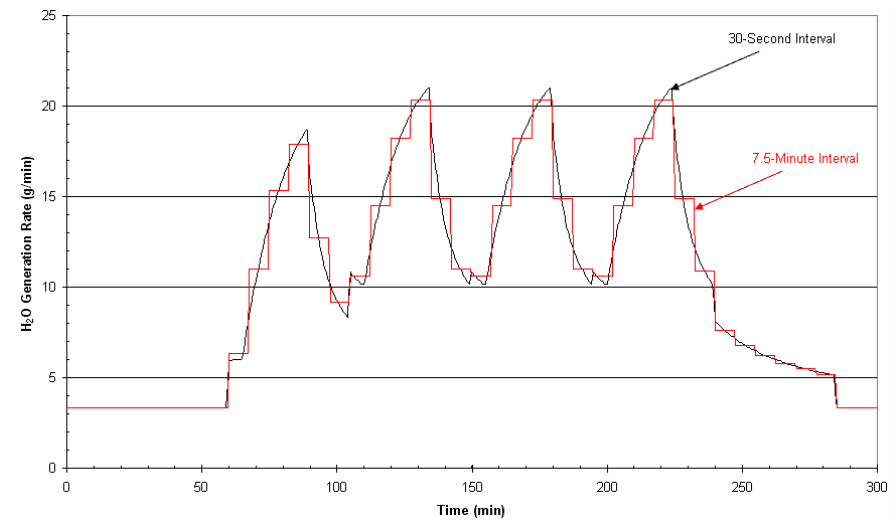

Figure 4 - Comparison of 4-Person Exercise Water Vapor Generation Rate Using 30-Second and 7.5-Minute Time Intervals $\left(75 \% \mathrm{VO}_{2} \mathrm{Max}\right.$, $5 \%$ Efficiency)

A standalone exercise scenario was tested in Phase 1, and three exercise scenarios were performed as part of the long test in Phase 2. All of the tests used $708 \mathrm{lpm}$ air flow rates and 6.5-minute spool valve cycle times. The chamber was maintained at $21^{\circ} \mathrm{C}$ throughout, except during the peak water load periods when the chamber chiller's temperature had to be increased slightly to avoid condensing on the heat exchanger coils. In the Phase 2 tests, the exercise scenario fell at a different time each simulated crew day, and the starting atmosphere conditions directly affected the peak atmosphere conditions, such that an exercise period only one hour after the crew woke up resulted in slightly lower peak dew points and $\mathrm{CO}_{2}$ concentrations than did an exercise scenario run later in the crew's day.

In general, the chamber dew points tracked the water input rates with a delay due to the time required to generate and inject steam in the HMS. Peak dew points in all four exercise instances were around $14-16^{\circ} \mathrm{C}$ at the end of the fourth crew member's active exercise period. $\mathrm{CO}_{2}$ partial pressures remained below 3.8 $\mathrm{mmHg}$ in all cases. Figure 5 shows a chart of the HMS input rates and chamber conditions during the Phase 1 exercise scenario. Note that the water input rate steps are not particularly crisp; this was a problem with the feedback control algorithms used for the HMS water pump, but the algorithm was improved for Phase 2 testing.

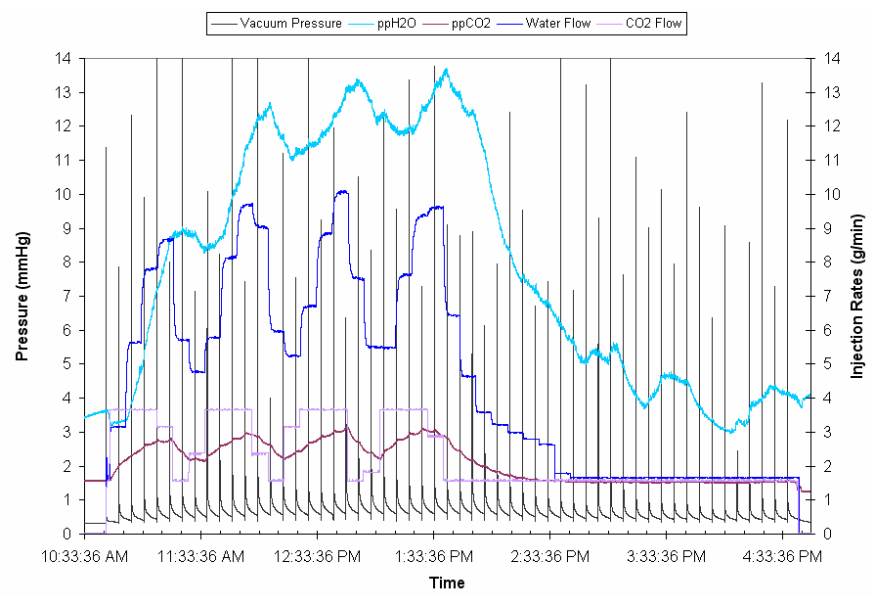

Figure 5 - Phase 1 Exercise Scenario Metabolic Constituent Input Rates and Resulting Chamber Conditions as Controlled by CAMRAS (need to rework for better B/W legibility and/or use $\mathrm{Ph} 2$ data)

\section{TEMPERATURE EFFECTS}

\section{Heat Transfer in the CAMRAS}

The CAMRAS is designed to promote even transfer of heat throughout the canister. Heat given off by the adsorption reaction in one layer is conducted through the aluminum foam, aluminum amine pellet retention screens, and aluminum body to the neighboring desorbing layers, which require heat to drive the desorption. Areas of the bed close to the edges do not receive as much benefit from the internal heat transfer as do those areas in the middle of the bed, due to their proximity to the relatively-poor heat transfer medium of the cabin air.

To better understand the distribution of heat within the CAMRAS, four temperature probes were inserted nearly to the core of the unit, one in an outside layer and one in a central layer, and a similarly-placed pair in the opposite bed. Surface temperature sensors were similarly placed on the centerline of the long edge of the unit. Several of these thermocouples can be seen in Figure 2. Figure 6 shows the readings from these sensors, plus the inlet and outlet temperature sensors on a single bed during a typical cycle during a larger crew baseline case run. It also shows typical vacuum pressure profiles as measured in the vacuum line just downstream of the CAMRAS. Note, however, that the height of the vacuum pressure spikes when the spool valve changes position are not necessarily accurate, due to the extremely brief period of the spike as compared to the $1 \mathrm{~Hz}$ data sampling frequency. 


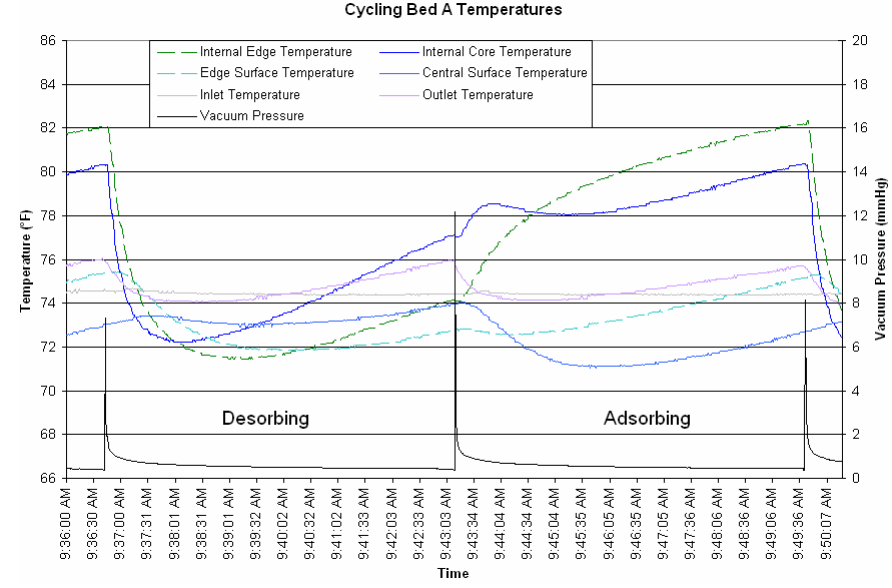

Figure 6 - Internal and Surface Temperatures of a CAMRAS Sorbent Bed During a Typical Cycle (convert to metric temps)

While the inlet temperature is stable throughout the cycle, the outlet temperature rises slowly through each half-cycle as a result of the exothermic adsorption process, and it falls again quickly each time the spool valve changes position. For the CAMRAS unit itself, surface temperatures vary much less than internal temperatures, as would be expected based on the heat transfer characteristics of the canister. The temperatures in the top and bottom layer of the canister vary more than the inner layers because they only have one adjoining layer to exchange heat with instead of two.

When the spool valve opens a bed to vacuum, its temperature quickly drops as the ullage air is rapidly pulled from the bed and desorption begins without the benefit of excess heat from the adsorbing bed. Temperatures in the desorbing bed then rise as heat is transferred from the adsorbing bed and the endothermic desorption nears completion. When the spool valve switches and the desorbing bed becomes the adsorbing bed, internal bed temperatures continue to rise as the adsorption process progresses. A small peak in the central internal reading just after the start of adsorption is likely related to the warmer air from the formerly adsorbing bed that flows in as the spool valve equalizes bed pressures on its way to the opposite position, and the heat is then quickly dissipated to neighboring beds. That small quantity of air, however, does not have enough thermal energy to noticeably affect temperatures closer to the edges of the unit.

\section{$\underline{\text { Testing at Different Temperatures }}$}

Because of these heat transfer characteristics of the CAMRAS, cabin temperature can affect its efficiency. To study the effects of cabin temperature, three cases were run with the standard $708 \mathrm{lpm}$ of air flow and 6.5-minute cycle times for both the smaller and larger crew loads at temperatures other than the standard $21^{\circ} \mathrm{C}$. The steady or nearly-steady chamber conditions achieved in a number of tests (baseline, temperature cases, and launch cases) are presented in Table 5, but note that these results were collected at varying points in time and test rig configuration, so some differences in the readings may be attributable to small changes in the test rig and test rig operations. In general, however, the lower the cabin temperature in the shirtsleeve comfort range, the more efficiently the CAMRAS seems to operate for both constituents. The variance in efficiency is probably not significant enough to drive operational decisions regarding cabin temperature maintenance under normal conditions.

\begin{tabular}{|l|l|l|l|l|l|}
\hline Cabin Temperature $\left({ }^{\circ} \mathrm{C}\right)$ & $\mathbf{1 5 . 6}$ & $\mathbf{2 1 . 1}$ & $\mathbf{2 3 . 9}$ & $\mathbf{2 6 . 7}$ & $\mathbf{3 2 . 2}$ \\
\hline $\begin{array}{l}\text { Small Crew } \mathrm{CO}_{2} \\
\text { Concentration (\%) }\end{array}$ & 0.19 & 0.20 & 0.20 & 0.21 & 0.22 \\
\hline $\begin{array}{l}\text { Large Crew } \mathrm{CO}_{2} \\
\text { Concentration (\%) }\end{array}$ & 0.28 & 0.28 & 0.29 & 0.29 & 0.31 \\
\hline $\begin{array}{l}\text { Small Crew Dew Point } \\
\left({ }^{\circ} \mathrm{C}\right)\end{array}$ & -8.2 & -8.8 & -4.0 & -7.1 & -5.2 \\
\hline $\begin{array}{l}\text { Large Crew Dew Point } \\
\left({ }^{\circ} \mathbf{C}\right)\end{array}$ & -3.3 & -1.1 & -2.4 & 0.9 & 0.7 \\
\hline
\end{tabular}

Table 5 - Chamber Constituents As Controlled by the CAMRAS for Various Chamber Temperatures

\section{VACUUM EFFECTS}

As previously mentioned, the earliest vacuum system implemented with the JSC test rig proved inadequate to handle the load of the CAMRAS test. Data gathered before the vacuum system was altered was still useful, however, in helping to illustrate the significance of vacuum pressure on the efficiency of the CAMRAS. Phase 1 data from the vendor comparison tests and the earliest attempts at baseline cases, plus that from later baseline cases with better vacuum and that from the deliberate degraded vacuum cases were all combined into a single chart to illustrate the general magnitude of the CAMRAS dependency on good vacuum. An array of preliminarily-calculated efficiencies versus cycling vacuum pressure are shown in Figure 7 . All the scenarios represented here were run at the standard 708 Ipm air flow rate and 6.5-minute spool valve cycle time in a $21^{\circ} \mathrm{C}$ chamber.

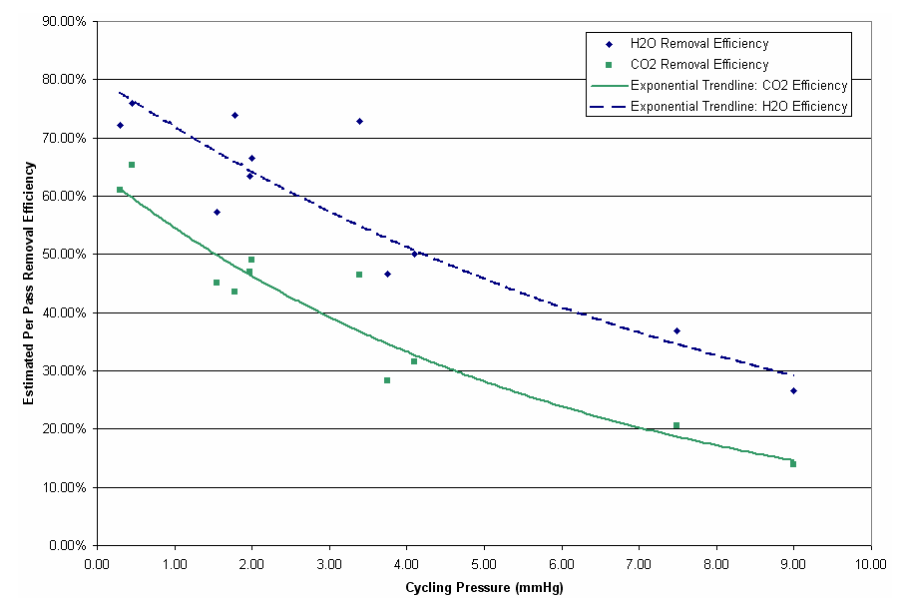

Figure 7 - CAMRAS Efficiencies versus Cycling Vacuum Pressure with Varying Atmospheric Constituent Loads 


\section{LAUNCH AND LANDING SCENARIOS}

Although the CAMRAS requires good-quality vacuum to operate efficiently for any length of time, vacuum will not always be available when the function of the CAMRAS is needed. Fortunately, the CAMRAS can still provide some constituent capture without a vacuum source to desorb to, and thus it can bridge the gap during transitional periods in the space flight such as launch and landing.

\section{Launch and Ascent}

The design of the CAMRAS has moved on since the design of the Phase 1 and 2 test article to include a pressurized gas purge for desorption on the launch pad. However, the question of how much time a wellscrubbed CAMRAS can provide for a crew without vacuum is still a valid concern for the period between liftoff and availability of space vacuum, as well as for potential contingency periods on orbit.

To that end, a launch scenario was performed in Phase 1. Both beds of the CAMRAS were left open to the vacuum system for at least twelve hours each prior to the start of test to ensure that as much of the previouslycaptured $\mathrm{CO}_{2}$ and water vapor as possible had been desorbed. The chamber was set up to have starting atmospheric conditions representative of the launch pad: $24^{\circ} \mathrm{C}$ temperature, $0.04 \% \mathrm{CO}_{2}$ concentration, and a dew point of $10^{\circ} \mathrm{C}$. The CAMRAS was operated at the standard $708 \mathrm{lpm}$ air flow rate and 6.5-minute spool valve cycle time and the temperature was maintained at $24^{\circ} \mathrm{C}$. Two runs were performed, one each for the smaller and larger crew size, and each case was timed from the beginning of metabolic load introduction and CAMRAS operation until the chamber $\mathrm{CO}_{2}$ concentration exceeded $1.00 \%$. The vacuum valve was then opened and the cases were then continued until the chamber reached steady state conditions with the temperature still at $24^{\circ} \mathrm{C}$ (see the steady state endpoints in Table 5).

During the portion of the test without vacuum, the CAMRAS inlet and outlet dew points start widely separated, then close to approximately $4.5^{\circ} \mathrm{C}$ apart and rising in parallel. The fact that they do not continue converging points to the great capacity for water adsorption by the SA9T amine. The inlet and outlet $\mathrm{CO}_{2}$ concentrations, however, did converge, indicating that all of the available $\mathrm{CO}_{2}$ adsorption sites had been filled. The plot in Figure 8 shows these inlet and outlet readings during the smaller crew launch case run.

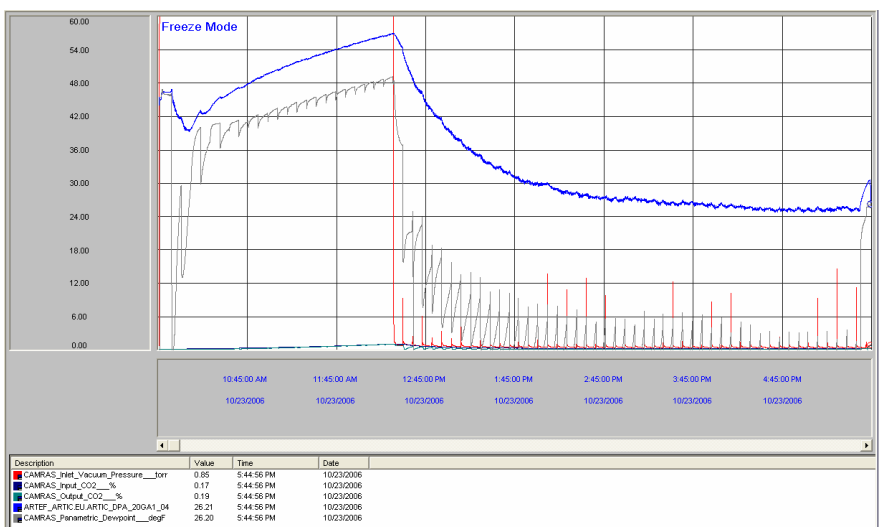

Figure 8-Smaller Crew Constituent Profiles at CAMRAS Inlet and Outlet During Launch Scenario (replace screenshot with partial pressure/metric units Excel plot)

For the smaller crew, the CAMRAS was able to adsorb $\mathrm{CO}_{2}$ for 137 minutes before the inlet and outlet concentrations converged at $0.88 \%$. The chamber exceeded $1.00 \% \mathrm{CO}_{2}$ concentration twelve minutes after that. The cabin dew point was about $14^{\circ} \mathrm{C}$ at that point. The vacuum valve was then opened to allow the CAMRAS to start desorbing as if the vehicle had reached orbit. The system took a period on the order of four hours to achieve typical operating chamber conditions from that point.

For the larger crew, $\mathrm{CO}_{2}$ was adsorbed for 97 minutes before inlet and outlet concentrations converged at $0.86 \%$, and the concentration reached $1.00 \%$ eleven minutes later. The peak dew point reading was compromised during this test run by a mismanagement of the HMS steam pressure, but it was in the same vicinity as that of the smaller crew scenario. The system again took roughly four hours after the vacuum valve was opened to bring the atmospheric constituent levels down to approximately baseline levels.

\section{De-orbit and Landing}

For the de-orbit and landing scenario, it was assumed that the CAMRAS had been operating at normal baseline conditions for an extended period before the beginning of the scenario. The vacuum valve was then closed and the system allowed to run, like the launch case, until the chamber $\mathrm{CO}_{2}$ concentration exceeded $1.00 \%$. The basic profiles of the constituent inlet and outlet curves were the same as for the launch cases when the vacuum line was closed. The duration of safe cabin condition maintenance differed from the launch cases due to the amine beds already having some base level of loading due to incomplete desorption during a normal 6.5-minute half-cycle and due to different starting atmosphere conditions. Another difference was that while in the launch scenario the vacuum lines between the CAMRAS and the vacuum valve were at ambient pressure, in the landing scenario they started at normal vacuum pressures and the pressure increased a little with each cycling of the spool valve and associated dump of ullage air into the vacuum line. For the smaller crew, the system was able to scrub $\mathrm{CO}_{2}$ from the atmosphere for 
about 120 minutes before saturation at $1.00 \%$. The chamber dew point was approximately $8^{\circ} \mathrm{C}$ at that point. $\mathrm{CO}_{2}$ concentration for the larger crew occurred after 103 minutes at $1.45 \%$, but $1.00 \%$ concentration was exceeded at 72 minutes and the dew point then was around $10.5^{\circ} \mathrm{C}$.

\section{FAILURE SCENARIOS}

For the purposes of Phase 1 testing, it was assumed that in the spacecraft the inlets of the three CAMRAS units (two operational and one closed-off spare) would be manifolded together in parallel with the outputs of two parallel fixed-flow blowers. The launch and landing scenarios examined the total capacity of the beds without vacuum, but "failure" scenarios were also tested that examined the capability of the system to maintain the cabin atmosphere at safe conditions if parts of the blower and CAMRAS system were rendered unusable. Three different scenarios were run with 6.5-minute spool valve cycle times and $21^{\circ} \mathrm{C}$ chamber temperatures:

1. One blower had failed, leaving one blower to feed both operational CAMRAS units. This case was essentially a matrix point tested before the Phase 2 matrix tests had been devised. The blower for the single test unit was simply run at half the standard flow rate with the chamber volume and larger metabolic load halved to simulate the existence of two CAMRAS units. With the blower running at 354 Ipm, the CAMRAS was able to maintain the chamber $\mathrm{CO}_{2}$ concentration at $0.48 \%$ and the dew point at roughly $9^{\circ} \mathrm{C}$.

2. One blower and two CAMRAS units had failed, leaving one blower and one unit to scrub the entire cabin volume with a larger crew's metabolic load. This was the worst-case scenario tested where the system was still usable. With the blower running at $708 \mathrm{lpm}$, the larger crew could still be kept safe indefinitely (though a smaller crew would not be allowed to exercise) by a single unit providing a $\mathrm{CO}_{2}$ concentration of $0.62 \%$ and a stable dew point of $8.8^{\circ} \mathrm{C}$.

3. Two CAMRAS units had failed, leaving one unit to do all the scrubbing, but with the increased airflow available from both operational blowers. The single test rig blower was commanded to run at double the standard flow rate, but could only push about half again as much air through the single unit due to excessive pressure drop. The steady flow rate through the single unit achieved $1020 \mathrm{lpm}$ with a pressure drop of $17 \mathrm{mmHg}$. (Pressure drop at the standard $708 \mathrm{lpm}$ was about $9.5 \mathrm{mmHg}$.) $\mathrm{A}$ chamber dew point of $6.4^{\circ} \mathrm{C}$ was maintained, along with a $\mathrm{CO}_{2}$ concentration of $0.54 \%$

In all these failure scenarios, therefore, it was demonstrated that the CAMRAS can readily maintain the cabin atmosphere at safe conditions for extended periods of time.

\section{RECOMMENDATIONS AND FUTURE TESTS}

Phase 1 and 2 testing provided a lot of useful data that may start shaping support equipment design and operations strategies. It also illuminated additional testing needed to further refine those issues and others that have not yet been investigated.

Most of the Phase 1 testing was done with a standard air flow rate of $708 \mathrm{lpm}$ and a spool valve cycle time of 6.5 minutes, and Phase 2 investigated a range of other flow rates and cycle times. While that operational combination might be appropriate for exercise loads, for most situations with normal and sleep metabolic loads it excessively dries the cabin and consumes significant blower power. A comfortable dew point in the cabin is in the 4 to $15^{\circ} \mathrm{C}$ range, but operational considerations on Orion will most likely limit the dew point to $10^{\circ} \mathrm{C}$ to prevent condensation on uninsulated cooling lines. Further matrix testing will be conducted to refine CAMRAS operational recommendations, but both variable-speed blowers and selectable spool valve cycle times would be wise implementations for the Orion in order to maintain the cabin at acceptable environmental conditions for the anticipated variety of crew sizes and metabolic loads. The possibility of requiring crew members to wear a liquid cooling garment during exercise periods to control water vapor coming from evaporated sweat has already been discussed.

Phase 1 testing clearly illuminated the need for good vacuum to enable effective desorption. This suggests that the CAMRAS vacuum line in the Orion should be as short and large as possible to allow desorbed gases to be quickly pulled away from the unit and into space. A longer and narrower line could significantly reduce the efficiency of the CAMRAS, and the blower speed and valve cycle time will need to be adjusted to try to account for the reduced performance.

Future test plans include investigation of the purge gas option for desorption while sitting on the launch pad, the further refinement of blower speed and valve cycle time recommendations, additional investigation of the effects of poor vacuum pressure, and closer examination of transitional periods between normal and failure conditions. Future tests will also rely more heavily on aluminum oxide moisture sensors and replumbed sample racks to avoid the sampling issues seen in Phases 1 and 2. Further testing may be run to study the system performance with reduced cabin pressure, crew members on breathing masks or sealed in pressure suits and connected to the cabin air loop via umbilicals, and with increased atmospheric oxygen concentrations. There is also considerable interest in the ability of the CAMRAS to handle and/or remove trace and gross contaminants. Some testing will be done on sub-scale units, but as much of the non-destructive testing as possible will be done on full-scale units. 


\section{CONCLUSION}

Over the course of four months, the performance of a compact and low-power amine-based system for regenerable carbon-dioxide and water vapor removal was tested in a realistic simulation of a spacecraft environment. It was proven that the unit was adequately sized to maintain a safe crew environment even in multiple-failure scenarios and it can easily handle normal metabolic loads. Early projections of operational blower speeds and valve cycle times might be scaled back to provide further power and ullage air savings because maximum efficiency may not always be required. Cabin temperature variations have relatively little effect on the performance of the unit, but access to a good vacuum source is very important for good operation. Further testing will incorporate improvements to the test rig, particularly in the areas of dew point sensing and metabolic water vapor generation. Planned future testing will refine operational recommendations, illustrate the effectiveness of a pressurized gas purge desorption for use on the launch pad, and investigate system effects on very small volumes such as breathing masks and pressure suits. All of this past and future data should prove useful in design considerations for the Orion spacecraft.

\section{ACKNOWLEDGMENTS}

The author would like to acknowledge Tim Nalette and Bill Papale of Hamilton Sundstrand for providing the test article and preliminary test data as well as technical support during the JSC tests and analysis insights. The entire JSC Exploration Life Support Air Revitalization team (Fred Smith, Jeff Sweterlitsch, Melissa Campbell, Sao-Dung Lu, Melissa Campbell, and Su Curley, plus John Graf) was instrumental in helping design the test points. Sao-Dung Lu provided significant support for Human Metabolic Simulator issues. Fred Smith and Sao-Dung Lu also assisted by performing some of the test cases, Jeff Sweterlitsch provided extensive assistance with data analysis, and Melissa Campbell facilitated many of the day-to-day test operations and assisted in the composition of this paper. This paper would not have been possible without all their help.

\section{REFERENCES}

1. Lin, A. " $\mathrm{CO}_{2}$ And Moisture Removal Amine Swingbed (CAMRAS) Phase 1 Interim Test Report", JSC65368, NASA Johnson Space Center, Houston, Texas, 2006.

2. Lin, A. "CAMRAS Phase 2 Quick-Look Test Report", NASA Johnson Space Center, Houston, Texas, 2007.

3. Nalette, T., et al. "Development of an Amine-based System for Combined Carbon Dioxide, Humidity, and Trace Contaminant Control", 05ICES-320, Society of Automotive Engineers, 2005.

\section{CONTACT}

\author{
Amy Lin \\ Mail Code JE77 \\ ESCG/Jacobs Technology \\ PO Box 58477 \\ Houston, TX 77258-8477 \\ 281-244-5121 \\ amy.b.lin@nasa.gov
}

\section{DEFINITIONS, ACRONYMS, ABBREVIATIONS}

\section{ARTIC: Air Revitalization Technology Integration Chamber}

Base Pressure: Vacuum system pressure when the CAMRAS test article is idle

CAMRAS: $\mathrm{CO} 2$ And Moisture Removal Amine Swingbed

CEV: Crew Exploration Vehicle

$\mathrm{CO}_{2}$ : Carbon Dioxide

Cycling Pressure: Asymptotic vacuum system pressure toward the end of each half-cycle when the CAMRAS test article is operating

ELS: Exploration Life Support

GAC: Gas Analyzer Console

$\mathbf{H}_{2} \mathbf{O}$ : Water

HMS: Human Metabolic Simulator

JSC: Johnson Space Center

NASA: National Aeronautics and Space Administration

RCRS: Regenerative $\mathrm{CO}_{2}$ Removal System 
ICES Abstract, 300 words or less

Session Code ICES30 (Regenerable Life Support Processes and Systems)

\title{
Testing of an Amine-Based Pressure-Swing System for Carbon Dioxide and Humidity Control
}

\author{
Abstract \\ Hamilton Sundstrand has developed a stable and efficient amine-based carbon dioxide \\ $\left(\mathrm{CO}_{2}\right)$ and water vapor $\left(\mathrm{H}_{2} \mathrm{O}\right)$ sorbent, SA9T, that is well-suited for use in a spacecraft \\ environment. The sorbent is efficiently packaged in pressure-swing regenerable beds that \\ are thermally linked to improve removal efficiency and minimize vehicle thermal loads, \\ and the flows are all controlled with a single spool valve. The SA9T sorbent technology \\ has already been baselined for the new Orion spacecraft. However, more data was \\ needed on the operational characteristics of the package in a simulated spacecraft \\ environment. This amine-based technology, referred to as the $\mathrm{CO}_{2}$ And Moisture \\ Removal Amine Swing-bed (CAMRAS) by the Exploration Life Support Air Team at \\ Johnson Space Center (JSC), was tested at JSC during the last third of 2006. Two series \\ of tests on the CAMRAS were performed at simulated metabolic loads of four and/or six \\ crewmen in a closed chamber. Tests were run at a variety of cabin temperatures and with \\ a range of operating conditions varying cycle time, available vacuum pressure, blower \\ speed, and crew activity levels. Results of this testing are presented and potential flight \\ operational strategies discussed.
}

